\title{
Using The Shift-Share Technique in Economies with Widely Varying Sectoral Growth Rates: Observations and a Suggested Model Modification
}

\author{
John R. Gordon, William B. Hackett \\ and \\ David Mulkey*
}

\section{INTRODUCTION}

Shift-Share is a descriptive tool of regional analysis which provides a systematic means of analyzing and categorizing economic change into component parts so that forces behind the change can be identified. It is also useful in organizing large quantities of data and in identifying the composition of past and existing economic structure. Consequently, shift-share analysis is widely used by regional economists to improve understanding of economic change in a region, county or community.

This article addresses a problem or peculiarity of shift-share analysis which arises when the technique is utilized in rapidly changing economies where a substantial portion of the change is concentrated in a few sectors. This feature of the shift-share technique can cause analysts and policy makers to focus unnecessary attention on the industrial-mix portion of the analysis. The article begins by briefly reviewing the traditional shift-share model. Then, the difficulty of utilizing the technique in rapidly changing economies with widely varying sectoral growth rates is identified and discussed. The final section discusses alternative procedural solutions to alleviate the problem. (It is a problem in application rather than in theory). This section also addresses the need for selecting relevant reference areas for shift-share analyses and suggests criteria to aid in the choice of regions. Finally, this section includes a discussion of a suggested model modification. The discussion and analysis focus on economies experiencing growth but, conceptually, the situation for declining economies would be analogous except for the direction of change.

\footnotetext{
* The authors are respectively, Associate Professor, Research Associate and Assistant Professor, Food and Resource Economics Department, Institute of Food and Agricultural Science, University of Florida, Gainesville, Florida. This manuscript is Number 3548 in the Florida Agricultural Experiment Station Journal Series.
} 


\section{THE SHIFT-SHARE TECHNIQUE}

The shift-share technique was originated in 1942 by Daniel Creamer. It received modest use by practitioners until a major publication by Perloff, Dunn, Lampard and Muth in 1960 and an extensive application by Ashby in a 1965 study of 3102 local areas in the United States.

Shift-share analysis identify's changes which have taken place in local (region, county or community) economic activity relative to changes in a reference area (usually the state or nation). Local area economic activity is first disaggregated into a number of sectors or industries, and level of activity in each sector is measured at the beginning and end of a set study period. Employment is generally used as the unit of measure although other measures of economic activity can be utilized.

For each local area and each industry in the area, shift-share analysis separates economic change into three parts and measures the contribution of each to total change in the economy. The first factor, the reference-area component, measures the change expected in the local area because of change in the reference area (of which the local area is usually a part). This effect is measured by multiplying base year employment in each local sector by the growth rate in total reference area employment between base and terminal years.

The second factor, the industrial-mix component, focuses on the distribution of fast and slow growing industries in the local area relative to the reference area. This component is traditionally calculated for each sector by subtracting the overall reference area growth rate from the growth rate of the specific industry in the reference area. The resulting deviation is then multiplied by base year employment for the same industry in the local area. The positive or negative sign on this component, respectively, designates the industry as relatively fast or slow growing in the reference area. When multiplied by base year employment in the respective local area industry, the industrial-mix component measures the expected deviation of that industry from the reference-area growth rate due to industry specific characteristics.

The final shift-share factor, the local- or competitive-share component, measures the competitive position of the local area and each industry in it relative to the base or reference area. This component is calculated by subtracting the local-area growth rate for each industry from the reference area growth rate for the same industry and multiplying the difference by base year employment for the local area industry. The positive or negative sign on this component indicates how the local area's proportionate share of employment in the industry fared in comparison to employment in the same industry in other local areas within the reference area. Positive values are generally accepted to mean that the local area has a set of unique factors (not specifically identified in the shift-share analysis) which give it a comparative advantage in attracting that industry. 
Following Gordon and Darling the shift-share components described above can be stated mathematically for industry $i$ in region $j$ as follows:

(1) $\Delta E_{i j}=\left(E_{i j}^{t}-E_{i j}^{b}\right)=R+M+L$

(2) $R=\left(\frac{E_{o O}^{t}-E_{o O}^{b}}{E_{o O}^{b}}\right) E_{i j}^{b}$

(3) $\mathrm{M}=\left[\left(\frac{\mathrm{E}_{\mathrm{io}}^{\mathrm{t}}-\mathrm{E}_{\mathrm{io}}^{\mathrm{b}}}{\mathrm{E}_{\mathrm{io}}^{\mathrm{b}}}\right)-\left(\frac{\mathrm{E}_{\mathrm{OO}}^{\mathrm{t}}-\mathrm{E}_{\mathrm{oO}}^{\mathrm{b}}}{\mathrm{E}_{\mathrm{oO}}^{\mathrm{b}}}\right)\right] \mathrm{E}_{\mathrm{ij}}^{\mathrm{b}}$

(4) $L=\left[\left(\frac{E_{i j}^{t}-E_{i j}^{b}}{E_{i j}^{b}}\right)-\left(\frac{E_{i o}^{t}-E_{i o}^{b}}{E_{i o}^{b}}\right)\right] E_{i j}^{b}$

where,

$$
\begin{aligned}
\mathrm{E} & =\text { employment, } \\
\mathrm{R} & =\text { reference area effect, } \\
\mathrm{M} & =\text { industrial mix effect, } \\
\mathrm{L} & =\text { local share effect, } \\
\mathrm{E}_{\mathrm{OO}}^{\mathrm{t}} & =\text { total employment in the reference area during the terminal period, } \\
\mathrm{E}_{\mathrm{oO}}^{\mathrm{b}} & =\text { total employment in the reference area during the base period, } \\
\mathrm{E}_{\mathrm{ij}}^{\mathrm{t}} & =\text { employment in industry } \mathrm{i} \text { in area } \mathrm{j} \text { during the terminal period. } \\
\mathrm{E}_{\mathrm{ij}}^{\mathrm{b}} & =\text { employment in industry } \mathrm{i} \text { in area } \mathrm{j} \text { during the base period, } \\
\mathrm{E}_{\mathrm{i}}^{\mathrm{t}} & =\text { employment in industry } \mathrm{i} \text { in the reference area during the terminal } \\
\mathrm{E}_{\mathrm{i} \mathrm{o}}^{\mathrm{b}} & =\text { employment in industry } \mathrm{i} \text { in the reference area during the base } \\
& \text { period. }
\end{aligned}
$$

These calculations are performed separately for each industry and then summed over all industries to yield shift-share components for the region.

\section{THE PROBLEM IDENTIFIED}

In a recent shift-share study of Florida and its sixty-seven counties two unexpected observations were made. First, the vast majority of industries in the state were categorized as relatively slow growing and, secondly, the most noticeable general feature of the county results was the overwhelming appearance of slow growing industries. The study encompassed the period 1965 
to 1975 and employment data for seventeen sectors were utilized. Florida served as the reference area from which county growth patterns were evaluated.

Table 1 shows that of the seventeen sectors only two - professional services and government employment - showed positive industrial mix effects for the 1965 to 1975 period. Since Florida is the reference area in the calculation of this table the local-share effects are zero. Very similar results were found for the individual counties. Only twelve Florida counties had a positive mix of industries although 53 counties had favorable local share effects and 45 counties had positive net shifts (industrial-mix plus local-share effect).

The overwhelming impression of a slow growing industrial mix in Florida and it's individual counties was not anticipated. Total employment in Florida over the ten year period increased 123 percent (Table 2) compared to 30 percent in the United States. Employment increases among the individual sectors varied widely, but with the exceptions of food and kindred products manufacturing and durable goods manufacturing, employment grew at rates exceeding 4 percent annually (Table 2).

Further examination of the analysis reveals that these results arise due to (1) the nature of employment growth in Florida and (2) the algebraic construction of $\mathrm{R}$, the reference area effect, in equation 2, and $\mathrm{M}$, the industrial mix effect, in equation 3. Addressing these causes in reverse order, the reference-area effect is calculated as the product of employment for a particular sector in the study area, $\mathrm{E}_{\mathrm{ij}}^{\mathrm{b}}$, and the average rate of increase in total employment for the reference area, $\left(\mathrm{E}_{\mathrm{oo}}^{\mathrm{t}}-\mathrm{E}_{\mathrm{oo}}^{\mathrm{b}}\right) / \mathrm{E}_{\mathrm{oo}}^{\mathrm{b}}$. This latter expression also enters into the calculation of $\mathrm{M}$, the industrial-mix effect, in equation 3 in such a way that the industrial-mix effect is inversely related to the size of the expression. $\left(\mathrm{E}_{\mathrm{OO}}^{\mathrm{t}}-\mathrm{E}_{\mathrm{OO}}^{\mathrm{b}}\right) / \mathrm{E}_{\mathrm{OO}}^{\mathrm{b}}$ is the average rate of increase for the various sectors with each sector weighted according to its respective share of total employment in the base year. The employment increase in Florida for 1965 to 1975 was 123.5 percent, a very rapid increase. (The unweighted mean rate of increase for the 17 sectors is 150.6 percent.) Yet, among the seventeen sectors there were wide differences in the rate of gowth. In particular, professional services employment increased 674 percent and employment in government increased 744 percent (Table 1). The remaining fifteen sectors averaged an increase of 76 percent in employment from 1965-1975. Not only was the growth rate very high in professional services and government employment, these two sectors accounted for more than 27 percent of total 1975 employment in Florida. Thus, as in the calculation of all mean values, the all industry $\left(\mathrm{E}_{\mathrm{OO}}^{\mathrm{t}}-\mathrm{E}_{\mathrm{Oo}}^{\mathrm{b}}\right) / \mathrm{E}_{\mathrm{oO}}^{\mathrm{b}}$ value in Florida is large because of the influence of the professional service and government sectors. As noted earlier, relatively large values of $\left(\mathrm{E}_{\mathrm{oO}}^{\mathrm{t}}-\mathrm{E}_{\mathrm{o}}^{\mathrm{b}}\right) / \mathrm{E}_{\mathrm{oo}}^{\mathrm{b}}$ will cause the industrial-mix effect, $\mathrm{M}$, to be small and, in fact, negative for most sectors.

Once a sector is classified as either relatively slow or fast growing in the reference area its classification remains the same in each of the subunits or, in this case, counties. However, the sectoral distribution of employment among 
TABLE 1

Selected Shift-Share Analysis Data for Seventeen Industries in Florida, 1965 and 1975

\begin{tabular}{|c|c|c|c|c|c|}
\hline Industry & $\begin{array}{c}1965 \\
\text { Employment }^{1}\end{array}$ & $\begin{array}{l}1975 \\
\text { Employment }^{1}\end{array}$ & $\begin{array}{c}\text { Change } \\
\text { In } \\
\text { Employment }\end{array}$ & $\begin{array}{c}\text { Reference } \\
\text { Area } \\
\text { Effect }^{2: 3}\end{array}$ & $\begin{array}{c}\text { Industrial } \\
\text { Mix } \\
\text { Effect }^{2: 3}\end{array}$ \\
\hline Resource Based & 16068 & 31722 & 15654 & 19844 & -4190 \\
\hline Construction & 123272 & 182462 & 59190 & 152242 & -93052 \\
\hline Food \& Kindred Prod. Mfg. & 42064 & 48432 & 6368 & 51949 & -45581 \\
\hline Other Nondurable Mfg. & 76955 & 119230 & 42275 & 95040 & -52765 \\
\hline Durable Mfg. & 127784 & 169913 & 42129 & 157814 & -115685 \\
\hline Transportation \& Utilities & 94733 & 170385 & 75652 & 116996 & -41344 \\
\hline Wholesale Trade & 95055 & 156644 & 61589 & 117394 & -55805 \\
\hline Building Materials & 16786 & 24007 & 7221 & 20731 & -13510 \\
\hline Food Stores & 47570 & 93290 & 45720 & 58749 & -13029 \\
\hline General Merchandizing & 116184 & 217148 & 100964 & 143487 & -42523 \\
\hline Automobile, Gasoline dealers & 45364 & 75056 & 29692 & 56025 & -26333 \\
\hline Eating \& Drinking Places & 66700 & 147703 & 81003 & 82375 & -1372 \\
\hline Finance, Insurance, Real Estate & 81984 & 182672 & 100688 & 101251 & -563 \\
\hline Lodging \& Amusement & 61810 & 120117 & 58307 & 76336 & -18029 \\
\hline Personal Business Services & 89689 & 197193 & 107504 & 110767 & -3263 \\
\hline Professional Services & 25445 & 196956 & 171511 & 31425 & 140086 \\
\hline Government & 62337 & 526284 & 463947 & 76986 & 386961 \\
\hline Total & 1189800 & 2659214 & 1469413 & - & - \\
\hline
\end{tabular}

'The data were provided by the Florida Division of Employment Security. There are many difficulties associated with data coverage. However. none of these difficulties are relevant to the central point of this article.

Reference area and industry mix effects were calculated according to equations 2 and 3

"Local share effect is not shown since all entries were zero because Florida served as the reference area.

counties and the reference area are different and an individual county can have relatively more or less of fast and slow growing industries. A study of the geographical distribution of the two very rapidly growing sectors - professional services and government employment - among Florida's counties revealed high levels of geographic concentration. Ten of the 67 counties accounted for 81 percent of the growth in professional services employment. Similarly, ten counties accounted for 67 percent of the growth in government employment. Eight counties were included on both lists.

The effect of this geographical concentration on the county shift-share analysis was to attribute the positive figures in the industrial mix portion of the analysis to a relatively small number of counties. Typically these were the central counties of standard metropolitan areas. But, the majority of Florida's counties had relatively small percentages of professional services and government employment growth and, consequently, very negative figures in the industrial-mix portion of the shift-share analysis.

So, although the shift-share results as described were unanticipated, they are mathematically correct. The pervading feeling of citizens and elected officials interested and involved with economic development in Florida is one of opti- 
TABLE 2

Selected Employment Data for Seventeen Florida Industries, 1965 and 1975

\begin{tabular}{lcccc}
\hline & $\begin{array}{c}\text { Distribution } \\
\text { of } \\
\text { Employment } \\
1965^{\prime}\end{array}$ & $\begin{array}{c}\text { Distribution } \\
\text { of } \\
\text { Employment } \\
1975^{\prime}\end{array}$ & $\begin{array}{c}\text { Industry } \\
\text { Growth } \\
\text { Rate } \\
1965-75\end{array}$ & $\begin{array}{c}\text { Proportion } \\
\text { of Total } \\
\text { Employment } \\
\text { Change } \\
1965-75^{\prime}\end{array}$ \\
\hline Industry & (Percent) & (Percent) & (Percent) & (Percent) \\
Resource Based & 1.35 & 1.19 & 97.4 & 1.06 \\
Construction & 10.36 & 6.86 & 48.0 & 4.03 \\
Food \& Kindred Prod. Mfg. & 3.53 & 1.82 & 15.1 & .43 \\
Other Nondurable Mfg. & 6.46 & 8.48 & 54.9 & 2.88 \\
Durable Mfg. & 10.74 & 6.39 & 32.9 & 2.87 \\
Transportation \& Utilities & 7.96 & 6.41 & 79.8 & 5.15 \\
Wholesale Trade & 7.99 & 5.89 & 64.8 & 4.19 \\
Building Materials & 1.41 & .90 & 43.0 & .49 \\
Food Stores & 3.99 & 3.51 & 96.1 & 3.11 \\
General Merchandising & 9.76 & 8.17 & 86.9 & 6.87 \\
Auto, Gasoline Dealers & 3.81 & 2.82 & 65.4 & 2.02 \\
Eating, Drinking Places & 5.61 & 5.55 & 121.4 & 5.51 \\
Finance, Ins., Real Estate & 7.56 & 6.87 & 122.8 & 6.85 \\
Logding \& Amusement & 5.19 & 4.52 & 94.3 & 3.97 \\
Personal Bus. Services & 7.54 & 7.40 & 119.8 & 7.32 \\
Professional Services & 2.14 & 7.41 & 674.1 & 11.67 \\
Government & 5.24 & 19.79 & 744.2 & 31.57 \\
Total & 100.00 & 100.00 & 123.5 & 100.00 \\
\hline
\end{tabular}

'Columns may not add to 100 percent because of rounding.

mism. The general negative connotations of the shift-share analysis could result in suggestions for further research and policy implications which tend to focus on improving the state's apparently slow growing mix of industries. However, further study shows that the slow growing mix of industries, as revealed in the shift-share analysis, is misleading and concentration on improving the mix of industries would divert attention from other economic development goals.

\section{SUGGESTED MODEL MODIFICATION}

Three alternative procedural techniques were considered in the application of the shift-share model to this particular growth situation. First, consideration was given to disaggregating the data into more sectors. Changing the reference area from the state to the nation was also considered. Finally, a model modification was made and is suggested for shift-share applications in similar growth situations.

Seventeen sectors were originally selected for study. Increasing the number of sectors might reveal some relatively rapid growing subsectors whose growth 
is presently masked in the existing aggregation. As emphasized by Houston in his often cited 1967 critique of shift-share analysis, the industrial-mix and local-share effects vary with the level of aggregation. Ashby (1968) observed that this problem is not unique to shift-share analysis and exists with many other analytical tools. To some extent, increasing the number of sectors is a trade-off with data availability and manageability.

The analysis was rerun for Florida with 80 rather than 17 sectors. As expected, disaggregating did improve the results as 18 of the 80 sectors showed growth rates higher than the state average versus two of 17 from the earlier analysis. A few manufacturing, finance, insurance and real estate as well as professional services and government sectors emerged in the fast growing category. However, the vast majority of sectors still appeared to be relatively slow growing. In addition, at the county level, particularly in rural areas, disaggregation is not always possible because of the confidentiality and unavailability of data.

Another possible solution to this problem is to change the reference or base area from Florida to some larger area, e.g., the southeastern region or the nation. Compared to almost any other base region employment growth in most Florida counties has been very rapid. The seventeen sector analysis was rerun for Florida and all of its counties using the United States as the reference area. Whereas in the original analysis only two sectors had growth rates exceeding the average employment growth rate in Florida, 16 of the 17 sectors had growth rates exceeding the employment growth rate in the nation. At the national level, nine of the 17 sectors experienced growth rates larger than growth in total national employment. County results appeared dramatically improved as well. In general, by utilizing the nation as the reference area rather than the state, the appearance of industry-mix and local-share effects was substantially improved.

Unfortunately, the literature on shift-share analysis provides little guidance to the analyst in selecting an economically relevant reference area. This is an important question which must be addressed in empirical applications. Consequently, a discussion of the importance of selecting relevant regions and some suggestions for choosing reference areas in shift-share analysis seem warranted.

The change in employment for an industry in a local area is a function of many factors which might be generally classified as economic, demographic, social, political, locational, resource related, and chance. Likewise, the change in employment for the same industry in the reference area is a function of many factors. These two sets of economic growth determinates will, very likely, have some factors in common and some remaining factors which influence employment change only in the study area or the reference area. The shift-share technique standardizes the employment change in the local area for the changes in the reference area and the remaining change, positive or negative, is revealed as the local-share effect. The local-share effect shows the 
change in the local area which cannot be attributed to changes in the reference area. As Houston has pointed out only the local share effect utilizes local data.

As discussed, the analysis separates economic change for each local area and each industry in the area into three components-reference area, industrial-mix and local-share. The results of the shift-share analysis for a local area must be interpreted relative to growth and mix of economic activity in the reference area. The numerical values of the three components as well as their signs, positive or negative, for an industry in a local area vary according to the choice of reference area. The nature of this relationship is revealed in equations 2-4. Therefore, the analyst's skill in selecting an appropriate reference area as well as his ability to interpret the results is critically important to the usefulness of the study.

Delineation of the proper region is a difficult task required in many regional studies. In contrast to many other types of studies, shift-share analysis requires the selection of two types of regions, the reference area and the regional or local study area(s). There are no inherent criteria within the model for selecting either of these two types of regions. Selecting the proper local study area(s) boundaries for a shift-share analysis is not an easy task but the considerations entering the decision criteria are not different from those common to other types of regional studies (Nourse, pp. 129-136). An area is delineated because it represents a functional economic trading center and/or it is reasonably homogeneous with respect to selected economic criteria, and, in practice, the economic criteria are compromised with other considerations, e.g. political, social, etc.

The choice of reference area involves many of the same considerations, but since the analysis of the local area(s) is influenced by the choice of reference area, careful attention should be given to selecting an economically relevant region for comparison to the local areas. One important consideration in selecting a reference area is the overall purpose of the investigation. Shiftshare analysis is useful when the general objective is to study the mix and growth of economic activity in the local area relative to the mix and growth in similar regions and the reference area. If the objective of the investigation is to study changes in the local area relative to a specified reference area such as the nation, state or multistate region, then the choice of reference area is fairly well determined at the onset of the investigation.

When the objective of the study emphasizes the comparison of change in one region to other similar regions the analyst has more flexibility and responsibility for selecting an economically relevant reference area. In such studies, the reference area selected should encompass as many factors common to economic development and growth in the various local areas as possible. At the same time, the reference area should be selected to avoid the introduction of factors which are relatively unimportant in influencing economic change in the local areas of study. If, for example, the purpose of an investigation is to study employment growth differences in North Dakota and Wyoming counties dominated by wheat production and large-scale coal mining developments, 
then inclusion of Florida counties dominated by citrus and tourism in the reference area will most likely not help and, in fact, will hinder the investigation by influencing the values and signs of the three shift-share components. By selecting a reference area which is relevant for understanding economic growth and development in the study areas, those influences shared in common with the reference area will be reflected in the reference-area and industrial-mix components of the analysis whereas the local-share effect will tend to reveal the change in economic activity resulting from a set of causes unique to each local economy. In practice, a reference area should be large enough to encompass the various local study areas as well as other areas which have some commonality or relevance to the economic development of the study areas but, after considering this criterion, a smaller reference area will generally be preferred to a larger area.

Although switching the reference area from the state to the nation improved the appearance of the results in this study of Florida counties, it is not particularly appealing from a conceptual viewpoint. The objective of this shiftshare study was to compare and contrast employment changes in any given Florida county with employment changes experienced in other Florida counties. Florida's counties share a set of institutional, locational, social, political and climatic factors which make the state rather than the nation the preferred reference area. Changing reference areas avoids the problem, but it does not directly address the difficulty.

A third alternative is to modify the shift-share model by changing the expression $\left(\mathrm{E}_{\mathrm{O}}^{\mathrm{t}}-\mathrm{E}_{\mathrm{O}}^{\mathrm{b}}\right) / \mathrm{E}_{\mathrm{oO}}^{\mathrm{b}}$ in equations 2 and 3. More specifically, it is suggested that this expression be replaced with the median growth rate, $\tilde{E}$, experienced among the sectors of the reference area. Equations 2 and 3 can then be restated as:

$\left(2^{\prime}\right) R=\tilde{E} \cdot E_{i j}^{b}$

(3') $M=\left[\left(\frac{E_{i o}^{t}-E_{i o}^{b}}{E_{i o}^{b}}\right)-\tilde{E}\right] E_{i j}^{b}$

This modification has the effect of reducing the reference-area effect and increasing the industrial-mix effect by a corresponding amount. Examination of equation 4 shows that the local-share effect is not affected by this change. In this study the $\left(\mathrm{E}_{(\alpha)}^{\mathrm{t}}-\mathrm{E}_{(\kappa)}^{\mathrm{b}}\right) / \mathrm{E}_{(0)}^{\mathrm{b}}$ value of 123.5 percent is replaced by the median value of 86.9 percent (Table 2). As explained, the 123.5 percent is larger because of the effect of the very rapid growth rates in professional services and government employment.

Rerunning the shift-share analysis for Florida and its counties utilizing the median value in the reference (state) area component produced changes in the anticipated directions. In the conventional analysis only two industries had individual growth rates exceeding the state average (weighted mean), while with the modified model eight of the seventeen industries had growth rates ex- 
ceeding the state average (median). This results by definition of a median. However, the eight sectors identified as having a positive industrial-mix include many industries which are generally understood to be rapidly growing. These eight include government; professional services; personal and business services; lodging and amusement; finance, insurance and real estate; eating and drinking establishments; food retailing; and resource based industries.

Results of the individual county analyses were also improved. Forty-seven counties revealed positive mixes of industry using the modified model. Previously only twelve were included in this category. Also, as expected, the modification did not change the county-or local-share effects. However, since there are adjustments made in the industrial-mix component, the number of counties with a positive net shift (industrial-mix plus local-share effect) increased from 45 to 60 using the modified model.

Since the shift-share model merely categorizes change into three components, there are no theoretical reasons for not modifying the model in this manner. In fact, it is well known that mean values are influenced by extremes. Median values are often utilized when the distribution of observations is known to unduly affect the mean.

A disadvantage of this modification is that the median value is affected by the level of disaggregation, whereas the average (mean) reference-area effect in conventional shift-share analysis is not. Another disadvantage is that with this modification the mix component no longer sums to zero. Therefore, the graphic symmetry of the usual octant analysis (Ashby, 1965) no longer holds.

This suggested model modification in rapid, unbalanced growth situations does not change the performance order of the industries and, from the standpoint of theory, it is not required. However, the task of the analyst in explaining the results of the study to state, regional and local policy makers; government employees; and citizens interested in local economic growth and development is made easier with this modified model. Consequently the probability of focusing additional research and public policies in the economic development area on results which arise because of actual differences in the study areas rather than as a consequence of data configuration is greatly improved.

\section{SUMMARY}

Shift-share is a frequently utilized descriptive tool of regional analysis. The values and signs of the reference-area, industrial-mix and local-share effects for a given region are influenced by the choice of reference area. Therefore, when the objective of the study permits some discretion in the delineation of the reference area, it should be selected so as to encompass as many of those influences on economic growth that are common to the local areas as possible yet, at the same time, be chosen so as to limit the influence of factors and types of growth which are unrelated or unimportant in the study areas.

In those situations where growth or decline in the reference area has been rapid and the change is concentrated in a few sectors of the economy, the 
results of the shift-share technique although mathematically correct tend to misrepresent the nature of the change in the industrial-mix portion of the analysis. In those particular growth situations, it is suggested that the shiftshare model be modified to change the allocation made to the reference-area and industrial-mix effects. This modification improves the usefulness of the results for economic development policy recommendations.

\section{REFERENCES}

Ashby, L. D. "Growth Patterns in Employment by County, 1940-1950 and 1950-1960," U.S. Department of Commerce, Washington, D.C., 1965.

Ashby, L. D. "The Shift and Share Analysis: A Reply," Southern Economic Journal, Volume 34, January 1968, pp. 423-425.

Creamer, Daniel. "Shift of Manufacturing Industries," Chapter 4 of Industrial Location and $\mathrm{Na}$ tional Resources, December 1942, U.S. Government Printing Office, Washington, D.C., pp. 85-104.

Gordon, J. and D. Darling. "Measuring Economic
Growth in Rural Communities: The Shift-Share Approach," Southern Journal of Agricultural Economics, December 1976, pp. 73-78.

Houston, D. B. "The Shift-Share Analysis of Regional Growth: A Critique," Southern Economic Journal, Volume 33, April 1967, p. 15.

Nourse, Hugh O. Regional Economics, McGrawHill Book Company: New York, 1968.

Perloff, H. S., E. S. Dunn, E. E. Lampard and R. F. Muth. Regions, Resources and Economic Growth, The John Hopkins Press: Baltimore, Maryland, 1960. 